\title{
Nomenclature chaos averted with financial bailout
}

\author{
National University of Singapore funds arbiters of animal names.
}

\section{Daniel Cressey}

18 November 2013 | Corrected: 18 November 2013

Every year scientists describe thousands of new species, but the body that regulates this process and rules on disputes between taxonomists warring over animal names has been facing financial meltdown. Now, in a deal announced today, the 'supreme court for animal names' has been bailed out.

The National University of Singapore will fund the secretariat of the International Commission on Zoological Nomenclature (ICZN) for the next three years. The commission arbitrates on disputes between scientists over naming of species, and produces the International Code of Zoological Nomenclature, which governs how species must be named.

"For 100 years after Linnaeus established bio-nomenclature there were no rules. There was chaos," says Daphne Fautin, vice president of the ICZN and a zoologist at the University of Kansas in Lawrence. "The code brought some order to that."

With the charitable trust that previously funded the work of the commission down to its last few pennies, there was a risk, says Fautin, that "chaos will reign again".

That risk seems to have been averted by the new funding, which will amount to around 100,000 Singapore dollars (about US\$80,000) per year, according to Peter $\mathrm{Ng}$, director of the Raffles Museum of Biodiversity Research at the National University of Singapore and one of the 26 volunteer commissioners who make up the ICZN. The university is also funding the first meeting of all the commissioners, which is taking place in Singapore this week.

"For the commission to go into dissolution is not an acceptable option," says $\mathrm{Ng}$. "We are doing something important for zoology. Otherwise, there would be anarchy."

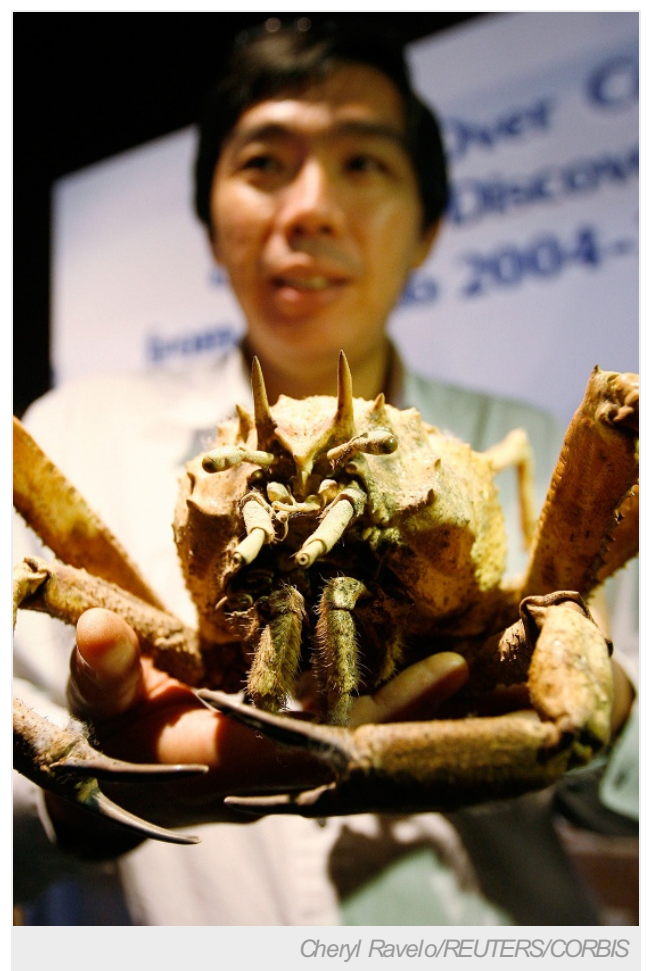

Peter $\mathrm{Ng}$ of the Singapore Raffles Museum of Biodiversity Studies — seen holding a deep-sea giant crab (Paramola macrocheira) - says that the body overseeing zoological nomenclature needs to re-invent itself.

\section{Challenges ahead}

The commission has faced some tough questioning in recent years as it has struggled with the rapidly changing face of taxonomy. Last year, after much clamouring from zoologists, the code was finally amended to allow species to be officially named in online-only publications.

The sheer number of species now being described — running to around 15,000 a year — has also presented challenges, admits $\mathrm{Ng}$. The three years of support from Singapore will allow the ICZN to reassess its financial situation and deal with the scientific challenges it faces, ahead of a new edition of the code scheduled for 2018. "It's time to re-invent ourselves," says $\mathrm{Ng}$.

The financial rescue of the ICZN is good news, says Mike Taylor, a palaeontologist at the University of Bristol, UK. The code needs to be able to evolve, he says - and that requires the guidance of the ICZN.

It is also crucial to have a body ruling on disputes, says Taylor, who has had a petition requesting a change to the 'type specimen' the animal that serves as the exemplar for a species - of a dinosaur called Cetiosaurus with the ICZN since 2009. He hopes that the new financial security for the commission might allow it to speed up its decision-making.

These disputes can seem arcane to those outside the taxonomic world. But Taylor says it is vital that they be settled and that words mean the same things to the same people: "Clear communication is the foundation of science." 
Nature | doi:10.1038/nature.2013.14191

\section{Corrections}

Corrected:An earlier version of the picture caption described the Paromola macrocheira as a "Philippine giant lobster"; it is a giant crab. 